\title{
Silent Journey: The Discovery of the Near-Death Experience of a Nonverbal Adolescent
}

\author{
Rick Enright, B.A., M.S.W., RSW \\ Thames Valley Children's Center, London, Ontario
}

\begin{abstract}
This article relates the story of a boy who had a near-death experience at the age of 8 , but who, because brain trauma left him quadriplegic and nonverbal, was unable to talk about his experience until I discovered it serendipitously 6 years later. Being able to tell his story and have his experience validated brought about significant changes in his emotional state, helped return personal control over his life, and ultimately led to his peaceful and fulfilling death
\end{abstract}

KEY WORDS: near-death experience, children, nonverbal communication.

Near-death experiences (NDEs) have been reported to occur frequently in children (Morse and Perry, 1990). The effects of NDEs on children have also been reported to be significant and long-lasting (Morse and Perry, 1992). Reports of NDEs among people who are nonverbal are quite rare, for obvious reasons (Serdahely and Walker, 1990). The following account is of the serendipitous discovery of an NDE experienced by a child who became nonverbal as a result of his near-death event. The consequences of this experience changed both his life and, ultimately, his death.

Rick Enright, M.S.W., is a social worker at the Thames Valley Children's Centre in London, Ontario. Reprint requests should be addressed to Mr. Enright at the Thames Valley Children's Centre, 779 Base Line Road East, London, Ontario, Canada N6C 5Y6; e-mail: ricke@tvcc.on.ca. 


\section{David's Background}

David was diagnosed with cystic fibrosis at the age of 3 months. While many patients with cystic fibrosis have benefited from improved drug therapy and now live well into adulthood, David's disease had a very rapid progression. By the age of 5 years, he had advanced cirrhosis of the liver. At the age of 8 , he was in liver failure and his family was given the option of almost certain death or a liver transplant. When a donor became available, they agreed to the surgery.

At around 22 hours after the surgery, David developed cerebral edema; his brain underwent massive swelling and the pressure resulted in what appeared to be an irreversible coma. The prognosis was grave and his family was told that he was virtually brain-dead. His vital signs were maintained, however, and after many days in a pediatric critical care unit, he began to recover spontaneously from his coma.

His physical state after recovery was drastically different from that before his surgery. Although the transplant had been successful and his new liver was working well, the damage to David's brain was massive. He had quadriplegia, with no useful function of arms or legs. He had lost the ability to speak. He aspirated anything he tried to swallow, and so was tube fed. He needed intermittent suctioning and ventilation. He was classified as medically fragile, so when he eventually went home it was with the maximum home-nursing support available.

The nonphysical impact of his brain damage was equally devastating. David had been an excellent student. He was an intelligent, goodnatured, and extremely sensitive boy, with the advanced maturity observed frequently in children with chronic illness or disability. His mother told me that before his surgery, she had heard him crying alone in his room one day. When asked what was wrong, he replied that he was sad because he was never going to be a father and that was something he really wanted to be. Sterility is a very common symptom of cystic fibrosis, so he was probably correct. Yet, how many 8-year-old children would know that, or shed tears over the potential loss of future parenthood?

David may also have had a premonition about his future. His parents had discussed with him the known risks of the choices available to them. The surgical risks included outright transplant failure, eventual rejection of the liver, or death due to complications. 
David, who by this time was visibly ill from his liver disease, said to his mother that he did not want to look worse than he already did. This was not an option that anyone had suggested, but it was precisely the outcome of his physical state after the coma.

\section{My Initial Work With David}

I first met David in the autumn of 1989 , about 2 years after his transplant. He was then 10 years old. David was a student in the special school program of the pediatric rehabilitation center where I work. He was unquestionably the most disabled child in the group. $\mathrm{He}$ was totally physically dependent upon caregivers for all his daily needs. He had a manual wheelchair, since he had no reliable means of controlling a power chair. He was nonverbal. To communicate, he used head switches attached to a voice generator (Keenan and Barnhart, 1993). The right switch activated the word "yes" and the left switch activated "no." The switches did not always function on cue, either due to mechanical problems or, more often, because David did not have enough control to make contact with them accurately. Over time, we relied less on the switches and more on eye-gaze direction: "yes" was gazing toward the right, "no" was gazing toward the left. He also used an eye-gaze coding system attached to the tray of his wheelchair for some common words and phrases.

David was moody, with sudden emotional swings being common. On good days, he had a wonderful sense of humor and enjoyed such activities as reading and art. However, there were frequent occasions when he would refuse to take any active role in lessons and he would often whimper or sob uncontrollably. At times he even had to be separated from the other members of the class because his distress was distressing to others. At other times, he could be cajoled into participation by telling him jokes. Generally he was quite passive, and over time his academic performance declined. Early on, there had been plans for some technological devices to assist with his communication. The use of a page-turner was considered so he could have the opportunity to read independently. He was also to be assessed for computer access or an electronic voice production system. Unfortunately, his attention span, his low frustration tolerance, and his frequent depressed moods sabotaged all efforts to make him more independent. Eventually, his vision deteriorated to the point where he 
could no longer use an eye-gaze system, and he was left with only his head turn to respond "yes" or "no."

During this time, my direct interventions with David were brief and superficial. He was a very physically and emotionally complex child and the stress on his regular caregivers was significant. I had no known means at my disposal to do any direct work with him, in addition to having no idea what, if anything, he wanted to do. I did, however, do intermittent supportive counseling with his mother, who was his primary caregiver. She was an extremely competent case manager and advocate, but she was dogged by emotional and physical exhaustion, systemic resistance and inertia, and a chronic battle for services.

In 1991, at the age of 12, David left the school in the treatment center and transferred to a special classroom in a local public school. I maintained contact with the family and the school, but did very little direct intervention with him.

This situation changed in the autumn of 1993 when David again came back into regular contact with me. Now 14, he transferred from his elementary school to a high school program in the city for students with physical disabilities. My colleagues and I had started a weekly support group the previous school year. It was facilitated by a multidisciplinary staff team consisting of a social worker, physiotherapist, occupational therapist, and speech language pathologist. When David arrived at this school he joined the group. There were up to 10 members in this group, ranging in age from 14 to 21 years. They had a variety of disabilities, including cerebral palsy, spina bifida, muscular dystrophy, and other mobility disorders. Most of them were full-time wheelchair users. Four of them had significant communication disorders.

In the previous year, I had made the observation that most of the members of this group had a very limited level of knowledge about themselves and their specific disabilities. Initially, this had caught me by surprise. Most of these young people had had long and intimate associations with doctors in our clinics, with hospital procedures, and with other services that dealt with their needs, including mobility, communication, and a variety of social and educational support systems. However, when asked about the specifics of their condition, most of them had considerable difficulty providing appropriate answers. For example, many of them had bladder or bowel continence problems, which required special toileting procedures or schedules, as well as attendant care. So I asked them during one group, as an exercise in developing independent skills, to imagine that I was a new 
teacher or employer who needed to know what their special needs were. Could they tell me some basic information about their disability, its implications, and any special procedures that I should know about? None of the group members could do so in any detail. Other than their basic diagnosis, they could not tell me the specifics of their condition, how they differed from others in the group, what were the symptoms they had to watch for in themselves, or why they had specific needs such as catheterization. I was appalled by this discovery and decided to take steps in the next school year to begin to educate them about themselves and their disabilities.

Shortly after David became a member of the group, over the course of several weeks we discussed different diagnoses in the group. We talked about the similarities, differences, possible causes, range of severity, and long-term implications of specific symptoms such as urinary tract infections, shunt blockage, medications, seizures, and other questions they raised themselves. After David agreed to this process, the group discussed his condition in terms of his two separate conditions: first his cystic fibrosis, and next his quadriplegia. I explained to the group that David had acquired symptoms similar to cerebral palsy as a result of brain damage after his surgery.

\section{David's Near-Death Experience}

David's mother called me the next day and reported that he had come home from school very agitated. With much questioning, she had learned from him that he was upset or excited about the group that day and he wanted to talk with me individually as soon as possible. As soon as I was able, David and I met privately at school. With the starting point supplied to me by his mother, there seemed to be some very obvious questions I could ask. In the following word for word transcript, as close as my memory can approximate, his responses appear in italics:

David, do you want to talk about your disability some more? Yes.

Do you want to talk about your cystic fibrosis? No.

Do you want to talk about your liver transplant? Yes.

Do you want to talk about the time before your surgery? No.

Do you want to talk about the time after your surgery? No.

You want to talk about during the surgery? Yes.

Okay, tell me where you were. Were you in the operating room? No.

Were you in the recovery room? No.

Were you somewhere else in the hospital? No.

Were you outside? No. 
At this point, I was starting to run out of logical alternatives, so I started to back-track in case I had missed something. I asked him, "Are we talking about the right thing?" He said, "Yes." I then asked if I was asking the right kind of questions. He said, "Yes," again, very emphatically. So I continued:

Were you on a bed? No.

Were you lying down? No.

Were you standing up? No.

Were you in a chair? No.

Were you on the floor? No.

Were you in the air? Yes.

I had asked this last question in a mixture of frustration and desperation, without the slightest expectation of what he would answer. The answer left me quite unprepared. My next line of questioning was to find out where he was or what he could see:

David, could you see something from the air? Yes.

Did you see equipment? No.

Did you see people? Yes.

Who could you see? Doctors? No.

Nurses? No.

Family? Yes.

All of them? No.

Your mom? No.

Dad? No.

Brother? Yes.

Grandmother? Yes.

Were they together? Yes.

Were they visiting you? No.

Were they talking? Yes.

Did you know what they were talking about? No.

Did they see you? No.

At several points during this narrative, David became visibly upset. When I asked about this, he assured me that he wanted to continue. I also checked several times to make sure that I was asking the appropriate questions, and he agreed that I was. He did not want me to stop. When our time was up, I attempted to summarize our discussion and give him some validation of his experience. I told him that I believed he had had an out-of-body-experience, that people in medical crisis reported such experiences frequently, and that he was not crazy. At this, he began to cry.

I called his mother later that day, and told her about this session. She was very surprised when I told her that David had seen his brother and 
grandmother. During the period immediately after his surgery, they had not been to the hospital, but had remained at home. If David had seen them, he had to have left the hospital to do it. I told her of my suspicion that David had an out-of-body experience. I also asked for, and got, her permission to continue talking to David.

When we met for our next session, I reviewed the first interview with David. He was very eager to continue our discussion. He confirmed all our findings with no changes. He gave an enthusiastic "Yes" when I asked if he wanted to continue. Using the same slow yes/ no question format, he explained that he next went someplace that was dark and empty. It was during this session that I suggested to David my belief that he had undergone a near-death experience. Without telling him the details of NDEs, I told him that I had done some reading about them, and that there were now thousands of case reports of people who had seen things similar to what he was reporting. I assured him that he was sane, that the experience was very real to him and others, and that if he wanted we would discover as much of his story as we could.

Over the course of the next several months, we continued to add details to what could reasonably be called a full-fledged, clinical neardeath experience. This discovery had extraordinary significance for David. We met weekly to continue the process. I began our sessions by asking him if he had more to tell me. If he said "Yes," then I would review briefly our last session and ask if there were mistakes. We would then carry on from there, using past context as the clue for where to go next. This process was frequently interrupted by blind alleys, wrong assumptions, and bad guesses on my part. When we seemed to be into a new area, I would stop every few minutes to ask him if I was asking the right questions. We gradually accumulated the following narrative:

After observing the conversation with his grandmother and brother, and his sense of a dark space, he then experienced moving through a long, dark passage toward a light. In the light he met beings who were familiar to him, although he could not name them and they were not people he knew here. They communicated with each other without talking. Although he felt as though he knew them, he was anxious and missed his family. At about this point, he was accompanied by a male figure who took him on a "guided tour." David described seeing fragments from both his past and his future. He was then either told or persuaded that he should return to his body. He had rather mixed emotions to this advice, wanting both to stay and to return to his family. His next memory was of gradually regaining awareness in the 
pediatric critical care ward, where he remained for many weeks until he was stable enough to be discharged home.

\section{Aftereffects of David's Experience and Our Discussions of It}

David's dominant feelings after returning to his body were frustration and anger about the circumstances to which he had returned. Prior to his surgery, he had expressed his fear to his mother that something awful was going to happen to him. He had been assured that everything was going to be fine. When he discovered that his negative premonition had been accurate, he was devastated. He had gone from being a curious, highly sociable boy to a state of extreme intellectual and social isolation, and total dependence on others for his care.

This was a very emotional process for David. During our first few weeks of work, he would frequently break into tears. Whenever I explored this, it was always a mixture of relief and frustration. He was greatly relieved finally to be able to tell this story, but frustrated by the limitations of the process, as was I. Gradually, his emotional vulnerability began to give way to a sort of philosophical sense of irony. We would hit dead ends where I could not find the right question to ask, and just agree to try again another day. He began to cry less, and laugh more. Initially he indicated he had been quite frightened by his experience.

The major factor here seemed to be the accumulated result of living absolutely alone with his memories of this experience with no way to share it and, more importantly, no way to be assured that what he saw was real. He was 8 years old at the time of his surgery and had no exposure to, or knowledge of, near-death phenomena. Although his experiences during the NDE had been pleasant, his interpretation of them was very confused and overall had frightened him. When we finally stumbled upon this experience, David was 15 years old. He had lived alone with this memory for more than 6 years. He frequently had wanted to talk about it but, until our accidental discovery, had never found a way to do so.

As we went along, I kept his mother informed of our conversations. I also let her know about questions or blocks we hit, and she would try from her much more intimate knowledge of her son to find new ideas to explore. About every 3 weeks, we got together to review what was happening, and try to assure ourselves that we were not crazy. 
This process began in October, 1993. It continued, off and on, for almost 2 years. From time to time we took breaks because of school holidays, David's frequent bouts with illness, and sometimes just because he asked for a break. But it was clear to all involved with David, including medical personnel, school staff, and his family that there was a clear and lasting change in David. From almost total passivity, he began to take an increasing role in attempting to communicate his needs and interests to others. His former persistent depression was largely alleviated.

For about 6 months, I did not mention the nature of the work I was doing with David to anyone but his family and several close professional colleagues. I also tried very hard to keep this as David's personal story and to give him control of how and when we continued. After we had outlined the majority of his experience, I recommended several books and a videotape about near-death experiences to his mother. I suggested that they use these to further validate his experience and to raise possible areas for future discussion.

About 7 months into this process, although we continued to work on his NDE narrative, David began to change the agenda of our meetings. He spent less time talking about the past, and began to identify some current issues. He began to request changes related to his communication system. He requested a case conference of his therapists and school staff to discuss the general topic of communication. I expected him to want to discuss computers, light talkers, or other augmentative devices. However, when the conference took place, what he wanted was for me to communicate his near-death experience to other members of the team. David's professional contacts were formidable. At school, he had occupational therapists, physiotherapists, speech language pathologists, teacher's assistants, a resource teacher, and nurses. He conveyed to us that his purpose in doing this was so that we could understand his emotional state and his frequent impatience with other people's agendas. He asked for a new wordbook with categories relating to death, medical issues, and emotional states, so that staff would be better able to understand his needs. We agreed that whenever possible we would give David as much information as we could about things affecting him, and that we would try to respond to his priorities as much as possible.

David's motivation for this meeting was something we discussed a number of times, and relates back to his experiences in school when he seemed moody and distractible and unresponsive. He was able to convey to me that during these times he was trying to make sense of his 
near-death experience and, in comparison to that, virtually nothing else seemed important. He wanted the people working with him to know that our priorities were not always his priorities.

This soon translated into a totally new agenda for our counseling sessions. David began to focus on issues related to his personal autonomy. He was able to identify that he was much brighter than he could convey to most people working with him, and that he wanted a larger role in making choices about his life. He was very specific about this in conversations with his mother, and he began to object to some of the regular treatments and procedures that were part of his routine. We discussed this in some detail just before summer holidays, and then David chose to take a break from counseling during the summer.

When we resumed work in September, a year after we had started, we sat down with a list of his medical treatments and went over them. We talked about what they did, their side effects, and what would happen if they were stopped. He then indicated what he wanted to happen. In about half of the cases, his choice was to terminate the treatment. This discussion took place several times between David's mother and myself, and his wishes caused some problems for her. Some of the treatments he wanted to end were significant and probably life-sustaining. After a number of long conversations with his mother, a meeting was requested with one of David's doctors to discuss the issue of continued consent to treatment.

Of particular concern to me were other professionals' perceptions of David's competence to give consent to treatment. It would have been easy to conclude in a brief assessment that David was seriously cognitively impaired. Subjectively, I believed he was not. I consulted with colleagues in medicine, psychology, and ethics regarding this issue. The general consensus was that the determination of competence in a person with severe physical and communication impairment could not be demonstrated by objective indicators only. In fact, for patients with severe impairment, formal testing almost always shows them to be seriously cognitively impaired because of the limitations of the testing and because of their inability to respond. I therefore wrote a formal assessment of my observations of David over a year of one-toone counseling. David and his mother took this note to the appointment, and with guidance from the doctor he was able to indicate clearly which treatments he wanted to continue and which he wanted stopped. The doctor involved treated David and his decisions with exemplary respect. By and large, David kept those treatments that would maintain his comfort level. Among the ones he chose to stop 
were intravenous antibiotics, a bronchodilator, and his anti-rejection drugs.

Following this appointment, in April, 1995, it was clear that David had made a major shift in focus. Our new dominant topic was death and dying. David's premature death had never been in doubt. Since his surgery, he had undergone several life-threatening illnesses, including pneumonia, gastric bleeding, and short-term rejection of his liver. His anti-rejection drugs kept him balanced on the narrow safe path between liver failure and kidney failure. His family had been told that his vision was in measurable decline and that he would probably undergo further perceptual and cognitive deficits over time. As our ability to communicate improved, David expressed repeatedly that he was in almost constant discomfort and occasionally in acute pain. The major complaint was tube feeding through a tube into his small intestine, which caused him frequent gastrointestinal discomfort. As his cystic fibrosis progressed, he suffered from chronic diarrhea, nausea, and vomiting. He was also producing copious mucous, which made suctioning a growing necessity. With this medical history as a backdrop, David began to make specific plans for his own death.

His first issue was to communicate with more people about what he had experienced. He asked me to talk to his brother, his estranged father, and other professionals about his near-death experience. He also asked me to convey his story to others who work with nonverbal clients because of his conviction that other people may have stories to tell and no way to tell them, unless someone asks the right question. Over the next several months, David chose to revisit these discussions repeatedly, and also began to refuse a growing list of medical interventions. In spite of the topic of these discussions, his attitude was philosophical, goodhumored, and, at times, serene. There was a great deal of laughter in our conversations. He expressed neither fear nor avoidance of death, although he was upset about leaving his family again. As part of this process, we reviewed his entire NDE. It remained consistent and, although it followed the classical pattern, retained details that were unique to him. At about this time, he also indicated that he had experienced other out-of-body experiences since his original NDE. He was quite insistent that these experiences were not dreams. He was also very specific that he knew he would die in the summer of 1995.

In June, 1995, we connected David with a palliative support team, which would facilitate his and his family's wishes that he should die at home. By July, David had terminated all treatments except digestive enzymes and tube feeding. He had requested their termination on 
numerous occasions, but his family had resisted because it felt to them like willful starvation. Finally, in August, we held a conference of all the family and professionals in David's living room. He was insistent, and he gave the same response to everyone who asked him: stop the drugs and take out the feeding tube. One of the telling arguments in this substantial moral dilemma was that the digestive enzymes were drugs, manufactured substitutes for the natural enzymes that are missing in a person with cystic fibrosis. David had systematically refused every other drug, so what made this drug any different? Yet, if he were granted this wish, then feeding him would be a completely meaningless gesture. Without those enzymes, food would pass mostly undigested through his body, bringing him little nourishment but considerable discomfort. We concluded that he understood the consequences of his decision, and the digestive enzymes were terminated that day. Two days later, his mother removed his feeding tube. He accepted only one medical intervention from then until his death: an intravenous line for the possible infusion of pain medication. He never needed to use it.

During the last week of his life, though he was now permanently in bed, he was conscious, alert, and utterly in control. We had the following conversation:

David, are we finished? Yes.

Have we done everything you wanted to do? Yes.

We have talked a lot about your NDE, but I suspect there is a lot I did not discover. How much of what happened to you have we found? Half? No.

More than half? No.

Less than half? Yes.

This last answer was accompanied by a spontaneous wide grin. He then managed to convey to me that he thought there were experiences he remembered from his NDE that perhaps he was not supposed to be able to explain. He died quietly at home less than a week later, two weeks before the end of summer vacation, 1995. His death was peaceful, unmedicated, and he was lucid until the end, surrounded by his family.

\section{Conclusion}

David left me a clear and specific legacy. He wanted this story told. His primary target audience was professionals and parents working with children with severe disabilities. It was his belief that somewhere there are others like him, who have been traumatized by medical 
crises or near-death experiences who could possibly benefit from the chance, however difficult or remote, to tell their story. I believe he was correct in that assumption, although I suspect that the special combination of circumstances, opportunity, motivation, and luck that contributed to this story will happen rarely. That in no way diminishes the importance of this story.

David's story contributes little that is new or different to the literature on near-death experiences. There are many stories more detailed and instructive in the existing literature. Neither is David's story unique because of his eventual death. Like many millions of people everywhere, his death left a huge void in the lives of his family and closest friends, but his passing was not newsworthy and history will take no notice of his brief life. What makes his story so important is what he was able to demonstrate through patience, persistence, and a desperation born of necessity that it is possible to be heard and understood even when all of the usual means to do so appear to be blocked. Most people, myself included, made the quick assumption based on his appearance and his functional limitations that David was helpless and totally dependent, and that his cognitive abilities were as damaged as his body. We were wrong. Ironically, David's NDE eventually gave him back control over his life, and ultimately, his death.

David also changed my life profoundly. What I previously knew about near-death experiences was based on a remote academic curiosity. David's experience gave me a window into a spiritual realm that I had never experienced in any personal or meaningful way. I do not know with any certainty what David experienced, but I now believe that there are facets to physical reality that we have not yet begun to understand, which demand, at the very least, an open and wondering mind. That key alone has the power to open doors that can lead us to discoveries we have not even imagined. I will never again look upon any of my severely impaired, nonverbal patients without wondering what they may want to tell me if they only had the means; and I will try to find the means. If this experience helps someone, somewhere, to break through the physical barriers and feel connected instead of isolated, then it will vindicate David's wish.

\section{References}

Keenan, J. E., and Barnhart, K. S. (1993). Development of yes/no systems in individuals with severe traumatic brain injuries. AAC: Augmentive and Alternative Communication, 9, 184-190. 
Morse, M. L., and Perry, P. (1990). Closer to the light: Learning from the near-death experiences of children. New York, NY: Villard.

Morse, M. L., and Perry, P. (1992). Transformed by the light: The powerful effects of neardeath experiences on people's lives. New York, NY: Villard.

Serdahely, W. J., and Walker, B. A. (1990). The near-death experience of a nonverbal person with congenital quadriplegia. Journal of Near-Death Studies, 9, 91-96. 